\title{
A Numerical Study of Non Structural Masonry Walls with Bed Joint Reinforcement subject to Flexure
}

\author{
E.A. Oliveira ${ }^{1}$, R.M. Silva ${ }^{2}$ and P.B. Lourenço ${ }^{3}$ \\ ${ }^{1}$ Faculty of Civil Engineering, Fumec University, Belo Horizonte, Brazil \\ ${ }^{2}$ Department of Engineering of Structures \\ Federal University of Minas Gerais, Belo Horizonte, Brazil \\ ${ }^{3}$ Department of Civil Engineering \\ University of Minho, Guimarães, Portugal
}

\begin{abstract}
This paper shows the numerical analysis of non structural masonry walls submitted to in plane bending and built with clay blocks. This behaviour is due to the excessive deformation of the load bearing structure. The walls of clay blocks were analyzed in two situations: with and without bed joint reinforcement. Models without reinforcement have been analyzed as reference specimens. In order to evaluate the improvement of structural performance with the proposed strengthening (reinforcement masonry walls) the displacements were measured in the middle of the walls, together with the crack width and the deformation of the steel bars. The program employed to carry out the numerical analyses was DIANA (version 9.1), that uses the Finite Element Method (FEM). The strategy adopted was macromodelling and non-linear physical behaviour. The results obtained from the numerical research proved that masonry walls with bed joint show a higher first crack load, better performance in service, increased capacity and larger displacement at failure. Improvements also in relation to the ultimate limit state, which indicates that it is beneficial that bed joint reinforcement is used in non structural and structural masonry walls.
\end{abstract}

Keywords: masonry walls, non structural, bed joint reinforcement, numeric analysis.

\section{Introduction}

Over the past decade, the way of building has been changed: the concrete progressed, the structures, the types are bolder and more precise masonry, the building process is not the same, neither the calculation nor the managerial techniques. The buildings are taller and slender, the design favors large spans, less pillars and the slabs thickness has reduced [1]. 
Usually the main changes were represented by the significant increase in the spans of beams and slabs, the increase in openings in walls or replacing massive masonry of other materials, including lightweight materials for placing directly on masonry slabs without being supported by beams. The concrete structures have become more flexible, which requires a careful analysis of their deformations and consequences [1].

However, beside the development of design and execution of work, there are still problems on buildings. The walls were more rigid with the introduction of stronger and larger hollow blocks, which reduced the capacity of walls to absorb deformation [2].

Therefore, it is mandatory to simplify and improve techniques and practice and moreover to better analyze the models that describe the reinforcement of masonry buildings. The aim of this paper is to study the masonry walls without structural function and cracking phenomenon associated with the deformation of structural elements are the scope of this article.

The Figure 1 shows a specific phenomenon where the support component deforms less than the component. The wall is behaving as a beam, resulting cracks similar to those presented for the case of bending of reinforced concrete beams [3].

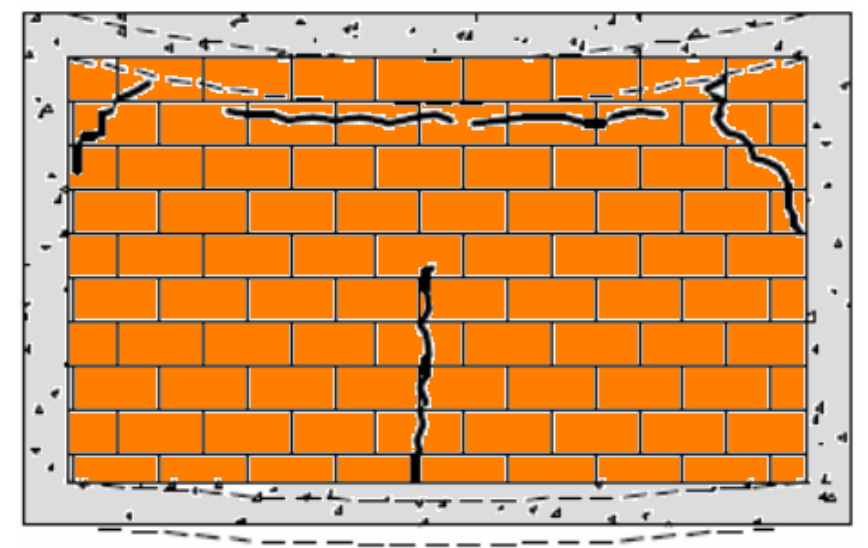

Figure 1 Deflection of the beam lower than that of the upper beam [3].

For this type of building analysis, it has been studied the insertion of reinforcement for masonry joints settlement blocks.

This is the lattice plane in which the crossbars are complementary in the same plane of longitudinal bars, most used, given the need to immerse the armor in the mortar and the limitations of the thickness of the joint.

Figure 2 presents an example of this technique (solution that was adopted for the design of the Sporting Club Stadium, Portugal [4]). 


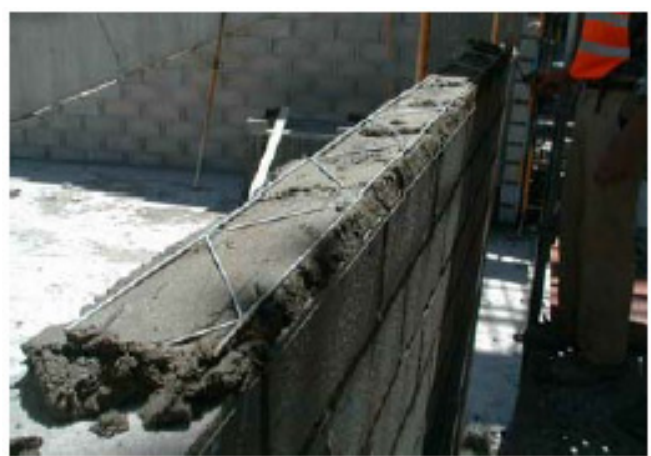

(a)

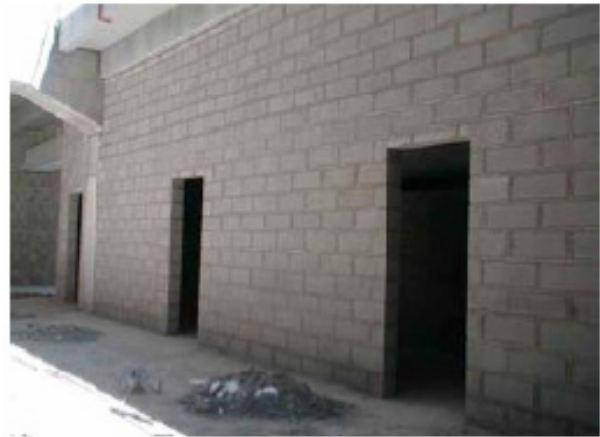

(b)

Figure 2 Sporting Club Stadium, Portugal: (a) implementation of bed joint reinforcement, (b) the final appearance of walls [4].

In order to evaluate the improvement of structural performance and efficiency of the proposed strengthening (reinforcement masonry walls subjected to bending in its plane), several numerical simulations of the mini-walls (with and without bed joint reinforcement) were carried out.

The methodology, the results and the analysis of the numerical simulations are presented in the following paragraph.

\section{Materials and methods}

In this study, it has been used the clay blocks with six holes without structural function, commonly used for fence walls in Brazil. The dimensions of these clay blocks and lattice plane are presented in Figure 3.

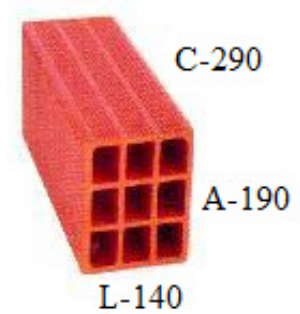

(a)

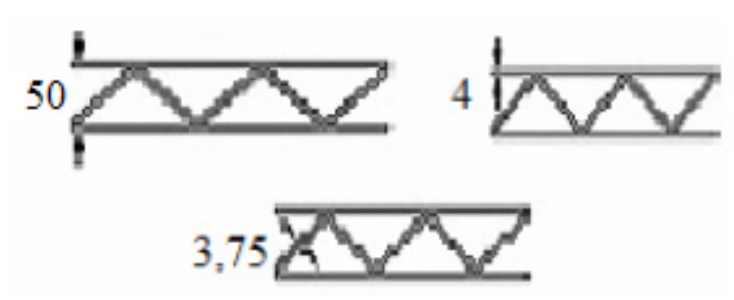

(b)

Figure 3 Details of the block and armor used in the construction of mini-wall $(\mathrm{mm})$ : (a) geometric characteristics of the clay block bored seal, (b) dimensions of the lattice plane with galvanized steel (Murfor / RND Z. 4 / 50). 
The numerical analysis were carried out using the program DIANA 9.1. It was used a non-linear and isotropic macromodeling analysis.

The loading was applied by successive vertical loads incremented until failure. The load application was implemented by the method of power control (as in the experimental analysis carried out in a series of mini-walls with the same characteristics of the models presented in Section 4 below). More details about the analysis and experimental results were presented on reference [5]

It should be mentioned that in the power control method, the iteration process is repeated until is reached an equilibrium within and acceptable range (defined as convergence criterion) [6].

The models were simulated with incremental loads, which aspects of this analysis and other concepts can be found on reference [6].

Table 1 presents the physical and mechanical properties of the lattice plane provided by the manufacturer.

Dimensional characteristics of the lattice plane

\begin{tabular}{|c|c|c|c|c|}
\hline \multirow[t]{2}{*}{$\begin{array}{l}\text { Type } \\
\text { RND- } \\
\text { Z. } 4 / 50 \\
\text { (1) }\end{array}$} & $(\mathrm{mm})$ & $(\mathrm{mm})$ & $(\mathrm{mm})$ & $\begin{array}{l}\text { Longitudinal } \\
\text { length } \\
\text { (m) }\end{array}$ \\
\hline & 50 & 4 & 3,75 & 3,05 \\
\hline
\end{tabular}

Physical and mechanical properties of armor

\begin{tabular}{|c|c|c|c|c|}
\hline Steel & $\begin{array}{c}\text { Tensile strength } \\
(\mathrm{MPa})\end{array}$ & $\begin{array}{l}\text { Yield strength } \\
\qquad(\mathrm{MPa})\end{array}$ & $\begin{array}{l}\text { Min. Resistence to } \\
\text { cutting and welding } \\
\text { (N) }\end{array}$ & $\begin{array}{l}\text { Weight } \\
(\mathrm{kg} / \mathrm{m})\end{array}$ \\
\hline \multicolumn{5}{|c|}{ (1) } \\
\hline 500 & 550 & 500 & 2.500 & 0,4 \\
\hline
\end{tabular}

${ }^{(1)}$ Armor type gland Murfor, A500 galvanized steel, with 2 bars $\phi 4 \mathrm{~mm}$ and spacing of $50 \mathrm{~mm}$ (RND-Z. 4 / 50) - with RND indicates "Round", Z galvanized, 4 the diameter of the bars (in $\mathrm{mm}$ ) and 50 the distance between the bars (in $\mathrm{mm}$ ).

Table 1 - Physical and mechanical properties of the lattice plane.

In order to solve the systems of nonlinear equations it has been adopted a combination between the estimated incremental method with the Newton Raphson technique and the arc length (arc-length control) [7]. 
For the modeling were used continuous plain strain elements [7]. In the discretization of the masonry were used quadrilateral isoparametric plane elements with eight nodes for plane stress state (named CQ16M), with Gauss integration (QU8). The characteristics of this element, such as the shape and loading, are illustrated in Figure 4.
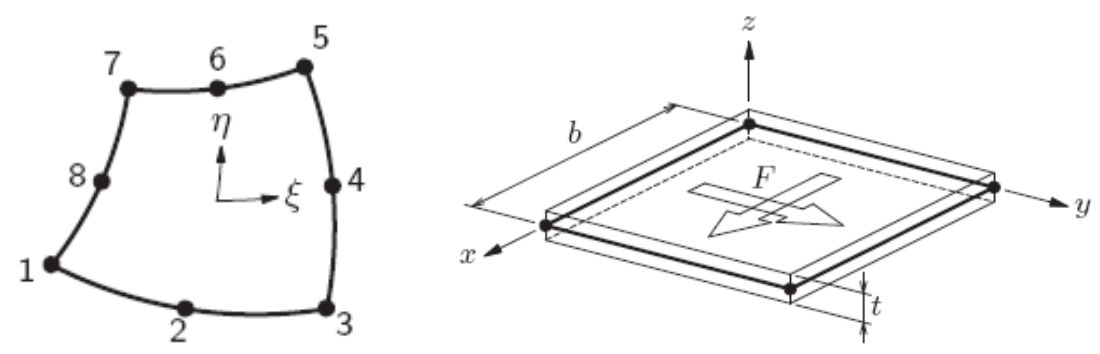

Figure 4 Elements used in numerical analysis: (a) quadrilateral isoparametric plane, element with eight nodes for plane stress state with Gauss integration (CQ16M) (b) characteristics of the element level [7].

Linear bar elements that have two nodes with two degrees of freedom per node, related to translations in the $\mathrm{X}$ and $\mathrm{Y}$ (reinforcement bar - straight line) were used for the discretization of the armor.

DIANA's program allows to immerse the reinforcement bars in the main structural elements (called "mother elements"), in this case, the elements used in the modeling of masonry (QU8 CQ16M).

Thus, the deformations of reinforcing bars are computed from the displacements that occur in major elements. This implies a perfect adhesion between the reinforcement and the material around them [7].

\section{Constitutive model}

In numerical analysis, the mechanical behavior of masonry was simulated by the plasticity model (part of DIANA) combine the Rankine criteria for tensile strength and Von Mises for tensile-compression, that is given by the following failure function (Equation (1) and (2)):

$$
\begin{aligned}
& f_{R}\left(\sigma, k_{R}\right)=\sigma_{1}-f_{t}\left(k_{R}\right) ; \quad \dot{k}_{R}=\dot{\varepsilon}_{1}^{P} \\
& f_{V M}\left(\sigma, k_{V M}\right)=\sqrt{\left(\sigma_{1}\right)^{2}-\sigma_{1} \sigma_{2}+\left(\sigma_{2}\right)^{2}}-f_{c}\left(k_{V M}\right) ; \dot{k}_{V M}=\sqrt{\frac{2}{3}\left(\dot{\varepsilon}_{1}^{P}\right)^{2}+\left(\dot{\varepsilon}_{2}^{P}\right)^{2}+\left(\dot{\varepsilon}_{3}^{P}\right)^{2}}
\end{aligned}
$$


Where:

- $\sigma_{1}$ and $\sigma_{2}$ are the principal stresses;

- $k_{i}$ are the internal variables of state or equivalent plastic deformation;

- $f_{t}\left(k_{R}\right)$ and $f_{c}\left(k_{V M}\right)$ are the tensile and compression tests, respectively;

- $\dot{\varepsilon}_{i}^{P}$ are the plastic deformations and the main point on the variable indicates the derivation with respect to time.

Figure 5 shows the graphical representation of the failure function.

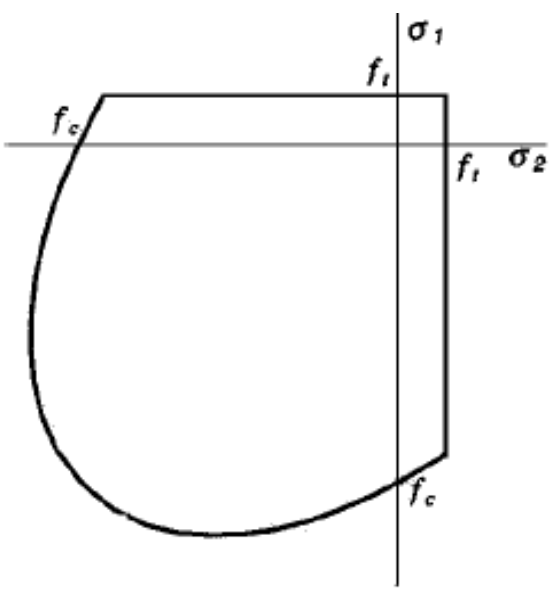

Figure 5 Graphical representation of failure function: combined failure criterions Von Mises - Rankine [6].

This combination of surface plasticity is especially applicable in situations of plane stress state, and was considered in this work due to its applicability and the availability of version 9.1 software DIANA.

Initially, it was assumed that the tensile strength $\left(f_{t}\right)$ was $0.10 f_{c m}$ that is $10 \%$ of the compressive strength of masonry. The fracture energy to traction $\left(\mathrm{G}_{\mathrm{ft}}\right)$ was adopted based on reference [6] and it values are presented in Table 2.

In order to reproduce the stiffness of the mini-walls obtained by experiments, the tensile strength and compressive modulus of deformation of the masonry were calibrated. The procedure used for calibration was described on reference [5]. 


\begin{tabular}{|c|c|}
\hline \multicolumn{2}{|c|}{ Elastic properties } \\
\hline $\begin{array}{l}\text { Masonry } \\
\begin{array}{l}\mathrm{E}=1,5 \mathrm{GPa} \\
\sqrt{ }=0,2\end{array}\end{array}$ & $\begin{array}{c}\text { Blocks filled with grouting } \\
\mathrm{E}=20,5 \mathrm{GPa} \\
\sqrt{ }=0,2\end{array}$ \\
\hline \multicolumn{2}{|c|}{ Inelastic properties } \\
\hline $\begin{array}{c}\text { Masonry } \\
f_{t, \text { alvenaria }}=0,1 \mathrm{MPa} \\
{ }^{3} G_{f t}=0,01 \mathrm{~N} \cdot \mathrm{mm} / \mathrm{mm}^{2} \\
\mathrm{f}_{\mathrm{c}, \text { alvenaria }}=0,33 \mathrm{MPa} \\
{ }^{3} G_{c}=0,50 \mathrm{~N} \cdot \mathrm{mm} / \mathrm{mm}^{2}\end{array}$ & $\begin{array}{c}\text { Blocks filled with grouting } \\
{ }^{1} f_{t, \text { graute }}=1,3 \mathrm{MPa} \\
G_{f t}=0,04 \mathrm{~N} \cdot \mathrm{mm} / \mathrm{mm}^{2} \\
{ }^{2} f_{c, \text { graute }}=13 \mathrm{MPa} \\
{ }^{3} G_{c}=20 \mathrm{~N} . \mathrm{mm} / \mathrm{mm}^{2}\end{array}$ \\
\hline \multicolumn{2}{|c|}{$\begin{array}{l}1 \text { The tensile strength }(\mathrm{ft}) \text { of the blocks filled with grouting } \\
\text { corresponds to } 10 \% \text { of compressive strength. } \\
2 \text { The compressive strength }\left(\mathrm{f}_{\mathrm{c}, \text { grout }}\right) \text { the blocks filled with grouting } \\
\text { was defined as follows }\end{array}$} \\
\hline \multicolumn{2}{|c|}{$f_{c, \text { graute }}=\left(\frac{f_{\text {graute }}+f_{\text {bloco }}}{2}\right) \times 0.5$} \\
\hline $\begin{array}{l}\text { being } f_{\text {grout }}=48 \mathrm{MPa}(\mathrm{c} \\
\text { obtained experimentally }[5] \\
\text { of the pack - set value acco } \\
\text { corresponds to the efficienc } \\
{ }^{3} \text { Values defined in accord }\end{array}$ & $\begin{array}{l}\text { ssive strength of the grouting } \\
k=4 \mathrm{MPa} \text { (compressive strength } \\
\text { o scientific publications) and } 0.5 \\
\text { (recommendations [8]). } \\
\text { ith the recommendations of [6]. }\end{array}$ \\
\hline
\end{tabular}

Table 2 - Material properties used in numerical analysis.

\section{$4 \quad$ Numerical analysis}

\subsection{Description of the models}

Initially, it was given consideration to the behavior of the three types of minimasonry walls without structural function when subjected to bending stress in their plan.

Figure 6 shows the types of the mini-masonry walls, namely $400 \mathrm{~cm} \times 120$ $\mathrm{cm} \times 14 \mathrm{~cm}$ (length $\mathrm{x}$ height $\mathrm{x}$ thickness).

The three types of models analyzed:

- Model 1 that corresponds to the mini-walls without armor (considered here as a reference) - (MOD 1 - Figure 6 (a));

- Model 2 corresponding to the mini-wall with armor at every two horizontal joints - (MOD 2 - Fig 6 (b)) and;

- Model 3 with lattice plane in all horizontal joints - (MOD 3 Figure $6(\mathrm{c}))$. 


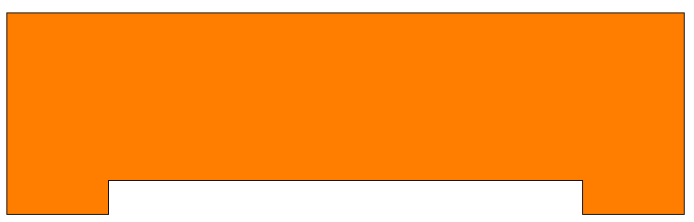

(a)

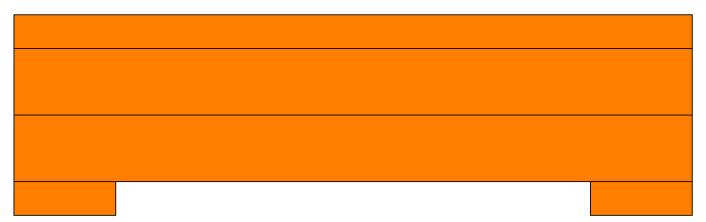

(b)

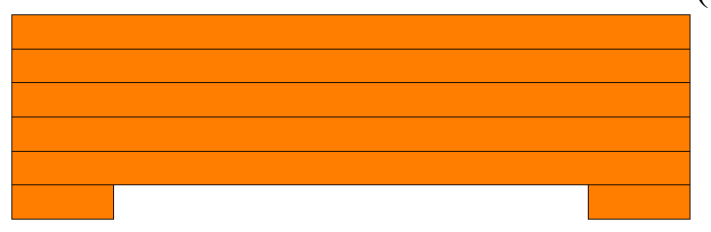

(c)

Figure 6 Models analyzed: (a) Model 1 (MOD 1) - non reinforcement, (b) Model 2 (MOD 2) - Lattice plane at every two horizontal joints, (c) Model 3 (MOD3) - Lattice plane in all horizontal joints.

Figure 7 shows the typical mesh used in numerical simulation. The gray elements (the filled ones) indicate the blocks filled with grouting, as used in the experimental study. These are the support blocks where the loads (central elements) were applied. These blockes were filled with grouting in order to avoid the crushing during application of the test load [5]. The red lines indicate the elements of bar ("reinforcement bar") used to mesh the bed joints reinforcement.

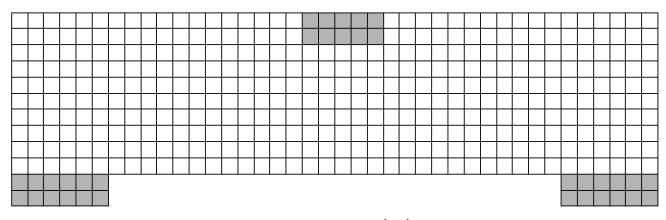

(a)

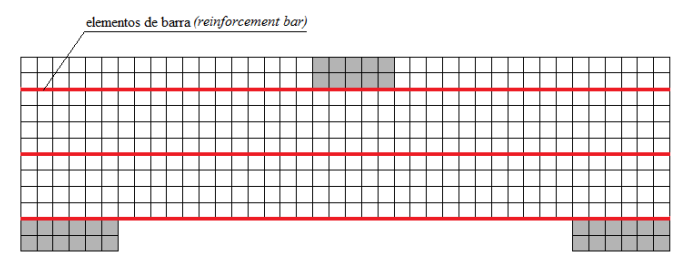

(b)

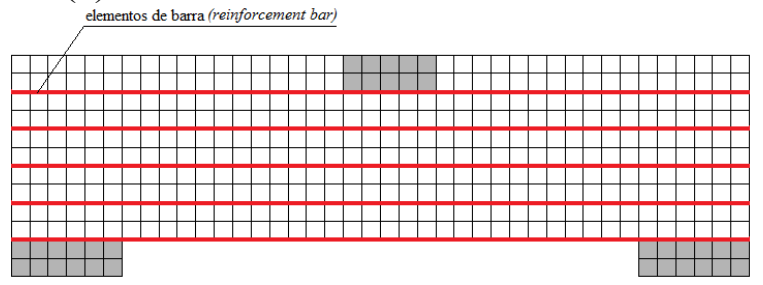

(c)

Figure $7 \quad$ Finite element mesh adopted for discretization of the models: (a) MOD 1 (b) MOD 2, (c) MOD 3.

Figure 8 shows the boundary conditions and where the load is applied through load control. 


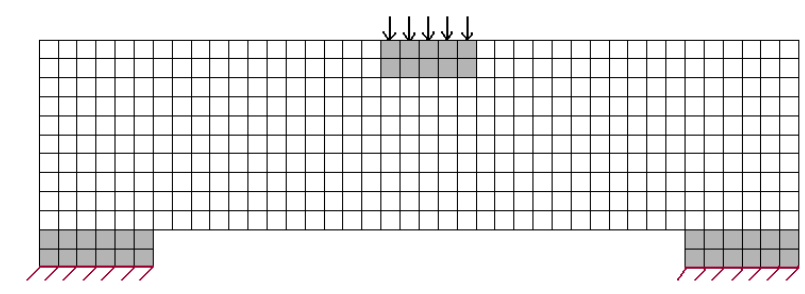

Figure 8 Load and boundary conditions used in the numerical analysis of the models.

\subsection{Results}

In order to analyze the behavior, performance and efficiency of the reinforcement technique adopted, the following issues were studied:

- the results during the first crack, in this case, the value of the total load applied and the deflection in the middle of the span, the distribution of stresses and strains;

- the cracking evolution in each model and;

- the behavior of the models during the application of vertical load based on the plot of the load versus displacement (curve of the central node).

\subsubsection{Model 1 (without bed joint reinforcement)}

Figure 9 presents the results obtained when the first crack occurred in MOD 1.

Through numerical simulation, it was found that in Model 1, the first crack occurred at mid-span for a load of about $9.17 \mathrm{kN}$ and the deflection in the central node was about $0.20 \mathrm{~mm}$. It may be seen that at the bottom center of the model, the maximum principal tensile stresses reached $0.112 \mathrm{MPa}$ closed to the tensile strength of the model $(0.1 \mathrm{MPa})$, causing a crack in the mid-span (as shown in Figure 9 (a)). The maximum principal strain (elongation) and minimum (shortening), in this region, had the following values $0,586 \mathrm{E}-4$ and $-0.365 \mathrm{E}-4$, respectively, (as shown in Figure 9 (c) and $9(\mathrm{~d})$ ).

It was also verified, the initiation of the plasticity in the vicinity of the support blocks and the formation of the arch effect by the deformation and by the distribution of the principal loads, (Figure 9 (b)).

The rupture of the model occurred to a load of about $17.0 \mathrm{kN}$ and numeric offset in the central node of approximately $0.9 \mathrm{~mm}$. Based on the analyzes of the results, it has been observed that the rupture occurred mainly due to cracks propagation and due to the lowering of the central blocks located at the top. 


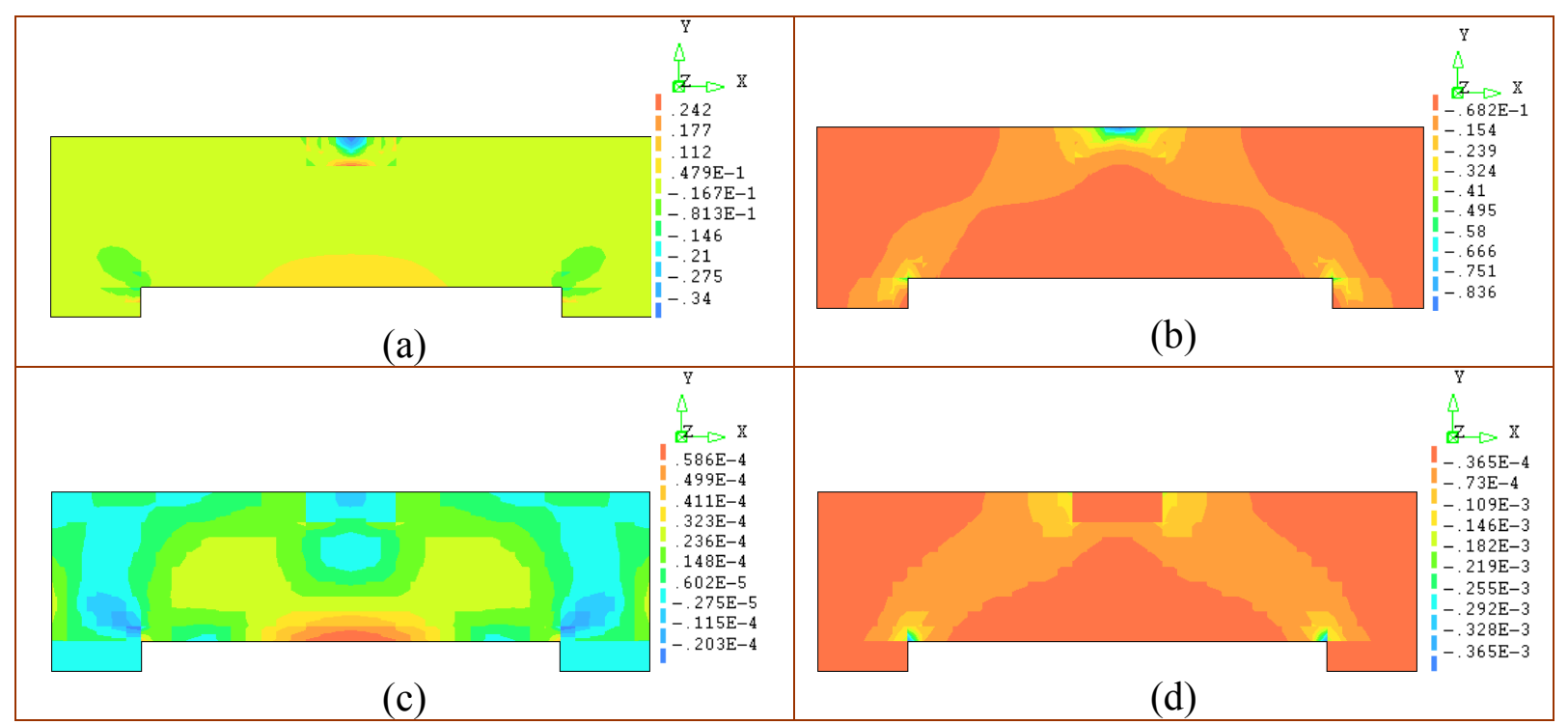

Figure 9 Numerical analysis results of Model 1 at first crack (load of $9.17 \mathrm{kN}$ ): (a) maximum principal stress, (b) minimum principal stress, (c) maximum principal strain, (d) minimum principal strain (units in $\mathrm{mm}$ and Newton).

\subsubsection{Model 2 (mini wall with reinforcement every two horizontal joints)}

The properties required to do the discretization of the armor based on the bar element used in numerical simulations were the elastic modulus, yield stress and transversal area of the longitudinal bars $(2 \phi 4.0 \mathrm{~mm})$, whose values are shown in Table 3.

\begin{tabular}{c|c}
\hline \multicolumn{2}{c}{ Armor joints } \\
\hline $\mathrm{E}(\mathrm{MPa})$ & 210.000 \\
$\sigma_{y}(\mathrm{MPa})$ & 435 \\
$\mathrm{~A}_{\text {stell }}\left(\mathrm{mm}^{2}\right)$ & 25 \\
\hline
\end{tabular}

Table 3 - Properties of armor joins used in numerical analysis.

Figure 10 shows the results corresponding to the load and the deflection at the moment when first crack occured: at a load of $10.6 \mathrm{kN}$ and displacement of the central node of $0.20 \mathrm{~mm}$. For this load level, the maximum principal stress was between -0.394 MPa (compression) and 0.249 $\mathrm{MPa}$ (tensile). 


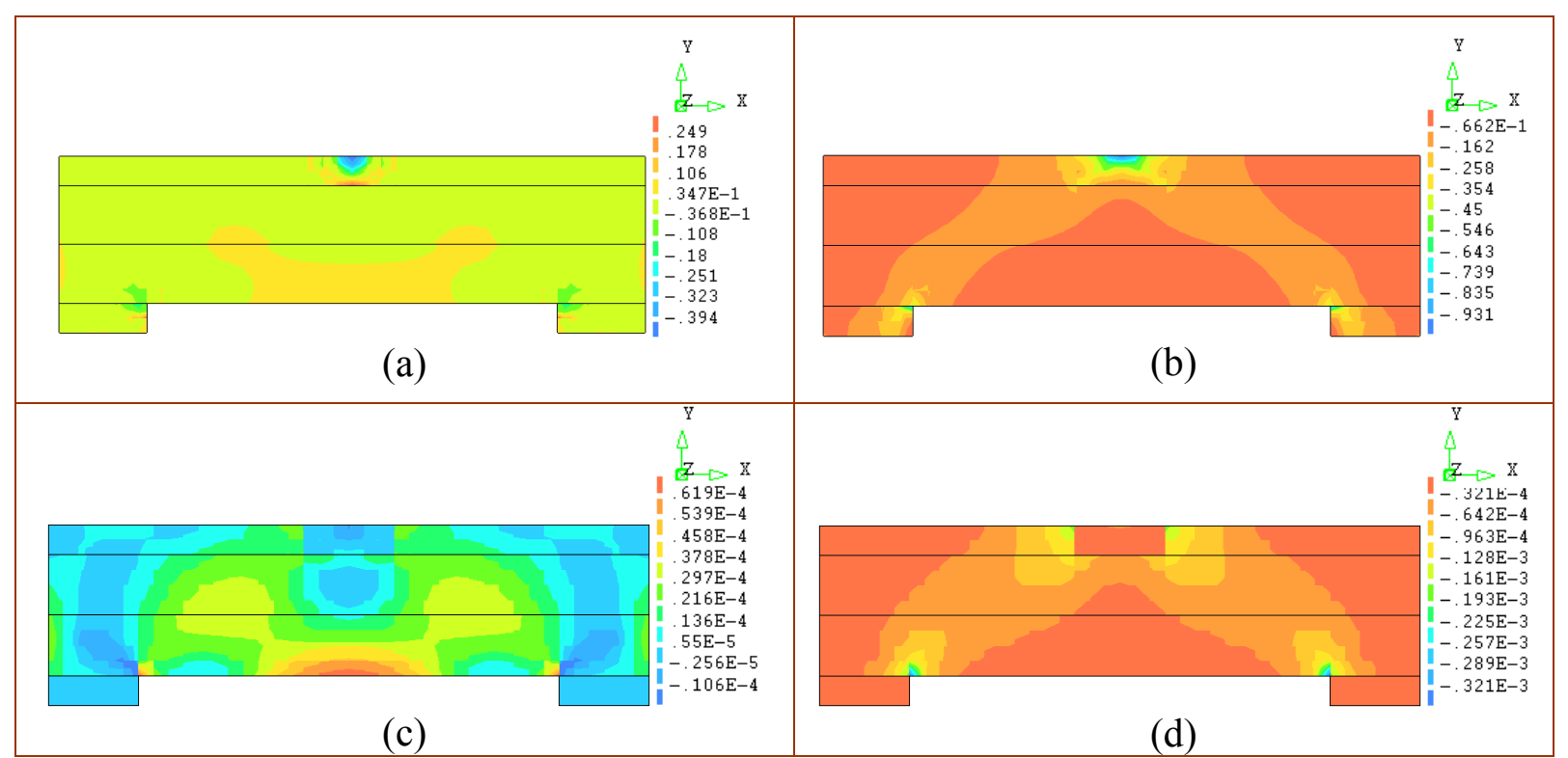

Figure 10 Numerical analysis results of Model 2 a load of $10.6 \mathrm{kN}$ : (a) maximum principal stress, (b) minimum principal stress, (c) maximum principal strain (d) minimum principal strain., (h) value of maximum principal strain at first crack (units in $\mathrm{mm}$ and Newton).

The maximum principal stress, at mid-span of the model, reached a value of $0.106 \mathrm{MPa}$ (tensile stress is superior to the tensile strength of the model - see Tab. 2 ). Whose thickness was less than the thickness of the first crack observed in MOD 1 , as the value of the deformation shown in figure 11. In this region, the maximum and minimum principal strain reached values around $-0.619 \mathrm{E}-4$ and $0.321 \mathrm{E}-4$, respectively (Figure 10 (c) and (d)).

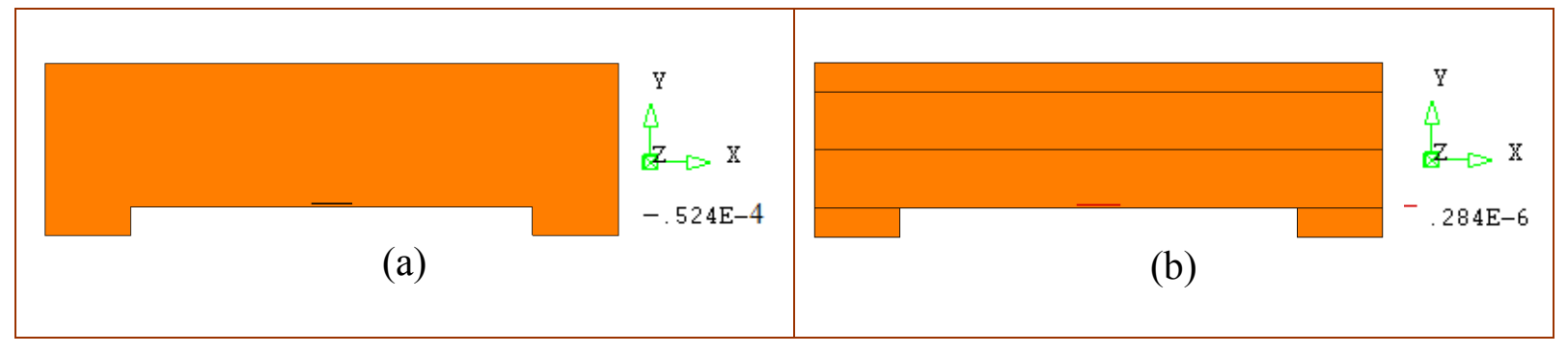

Figure 11 Value of maximum principal strain at first crack: (a) MOD 1, (b) MOD 2.

The obtained results a rupture by shearing and compression propagation of the central stresses in the support direction, with subsequent crushing of the elements that connect with the point of load application support. 
It is worth to mention that the Model 2 of the numerical simulation allowed to see the insertion of reinforcement in horizontal joints, beside this the ductility and resistance capacity of the model increased, and also the propagation of the cracks is different comparing with the model without reinforcement. Cracks have spread along the length of the model instead of concentrating on mid-span (region of highest tensile stress), as observed in the model without reinforcement (MOD 1).

The results of the numerical simulation showed that the bending cracks that arise at the inferior part of Model 2 were not the main cause of the rupture. In a final stage of loading, cracks were formed cutting with greater openness to the region that evolved with the support where there were small cracks on bending.

Figure 12 shows the stress distribution in the armor of the joints at a load level at about $10.6 \mathrm{kN}$ (equivalent load for the first crack); $16.5 \mathrm{kN}$ (equivalent load to the change in behavior of the model from the analysis of curve of the central node - figure 13). These results showed the contribution of the reinforcement in the resistance at the traction efforts by the cracking of the masonry due to the low tensile strength of this material.

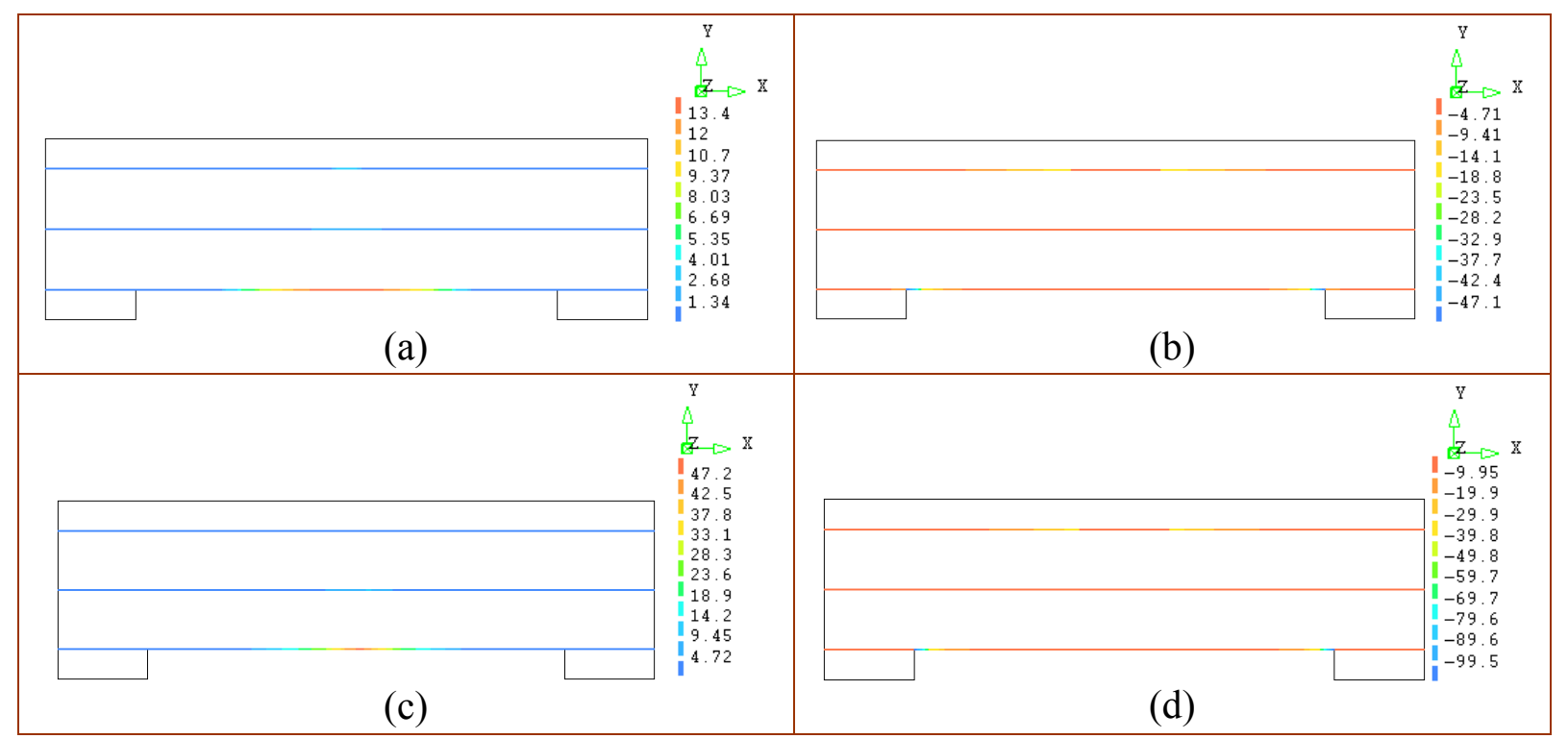

Figure 12 Distribution of principal stresses in the armor of joint (Model 2) at different load levels: (a) and (b) maximum and minimum principal stresses, respectively, for the load of $10.6 \mathrm{kN}$ and central deflection of $0.20 \mathrm{~mm}$ corresponding to the occurrence of first crack, (c) and (d) maximum and minimum principal stresses, respectively, for the load of $16.5 \mathrm{kN}$ and central deflection of $0.35 \mathrm{~mm}$ (units in $\mathrm{mm}$ and Newton). 


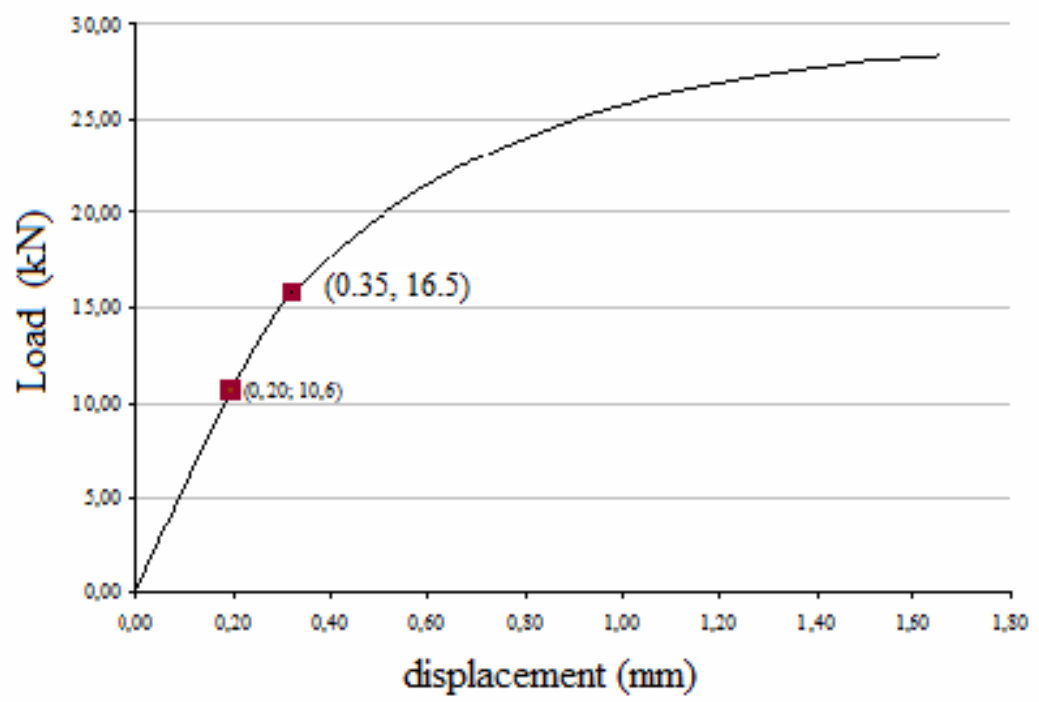

Figure 13 Curve of the central node (MOD 2): loads versus displacment.

It was also verified, that for the rupture load of $28.4 \mathrm{kN}$ the maximum principal stress in the armor of joints reached $17.3 \mathrm{MPa}$ (tension), that is about $40 \%$ of the yield stress of the armor.

\subsubsection{Model 3 (mini wall with armor immersed in all horizontal joints)}

Figure 14 shows the results for the a load of $10.8 \mathrm{kN}$ and displacement of the central node of $0.20 \mathrm{~mm}$, corresponding to the load and deflection at the first crack.

At this load level, the maximum principal stress vary between $-0.401 \mathrm{MPa}$ (compression) and $0.252 \mathrm{MPa}$ (tensile). In the middle of the span, where the first crack appears, the maximum tensile stress reaches a value around $0.179 \mathrm{MPa}$ (tension higher than the tensile strength of the model). The minimum principal stresses reached higher values in the upper center of the model $(-0.943 \mathrm{MPa})$ that propagate descendent in the direction of the support, as observed in models MOD 1 and MOD 2.

The maximum principal strain were stretching the middle of the span; but in other regions, these principal strain vary between -0.104 E-4 (shortening) and 0.225 E-4 (stretching) - see figure 14 (c). As it is shown in figure 14 (d), the minimum principal strains were shortening the entire model, being higher in the upper corners near the supports.

As in Model 2, the displacements in the middle became larger for the action of the load of approximately $16.5 \mathrm{kN}$ and displacement of the central node equal to $0.30 \mathrm{~mm}$. It was also verified that most of the cracks were at the middle of the span, which caused lost of stiffness and the increase of the displacement at the central node. The maximum principal stresses reached values around $0.352 \mathrm{MPa}$ and -0.621 $\mathrm{MPa}$. In the middle of the span, the maximum tensile strength reached a value 
around $0.244 \mathrm{MPa}$ (tensile stress exceeding the tensile strength of the model) - see figure 15 .

The biggest strains were obtained in the fissures cutting approximately $0.237 \mathrm{E}-2$. As in Model 2, it was observed that at the end of loading there were observed shear cracks with the biggest opening, and the bending cracks were not predominant in rupture.

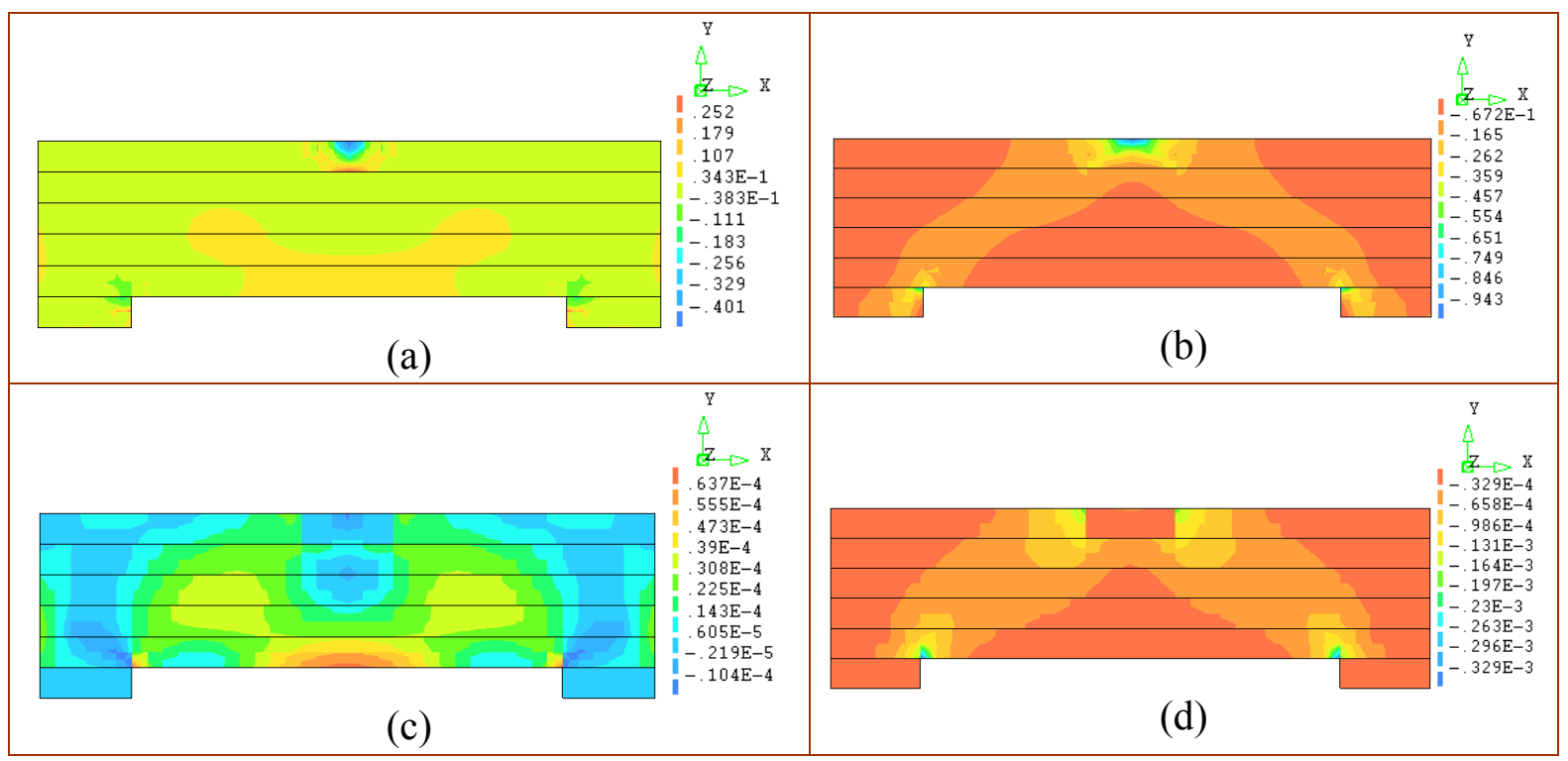

Figure 14 Results of Model 3 for a load of $10.8 \mathrm{kN}$ : (a) maximum principal stress, (b) minimum principal stress, (c) maximum principal strain, (d) minimum principal strain (units in $\mathrm{mm}$ and Newton).

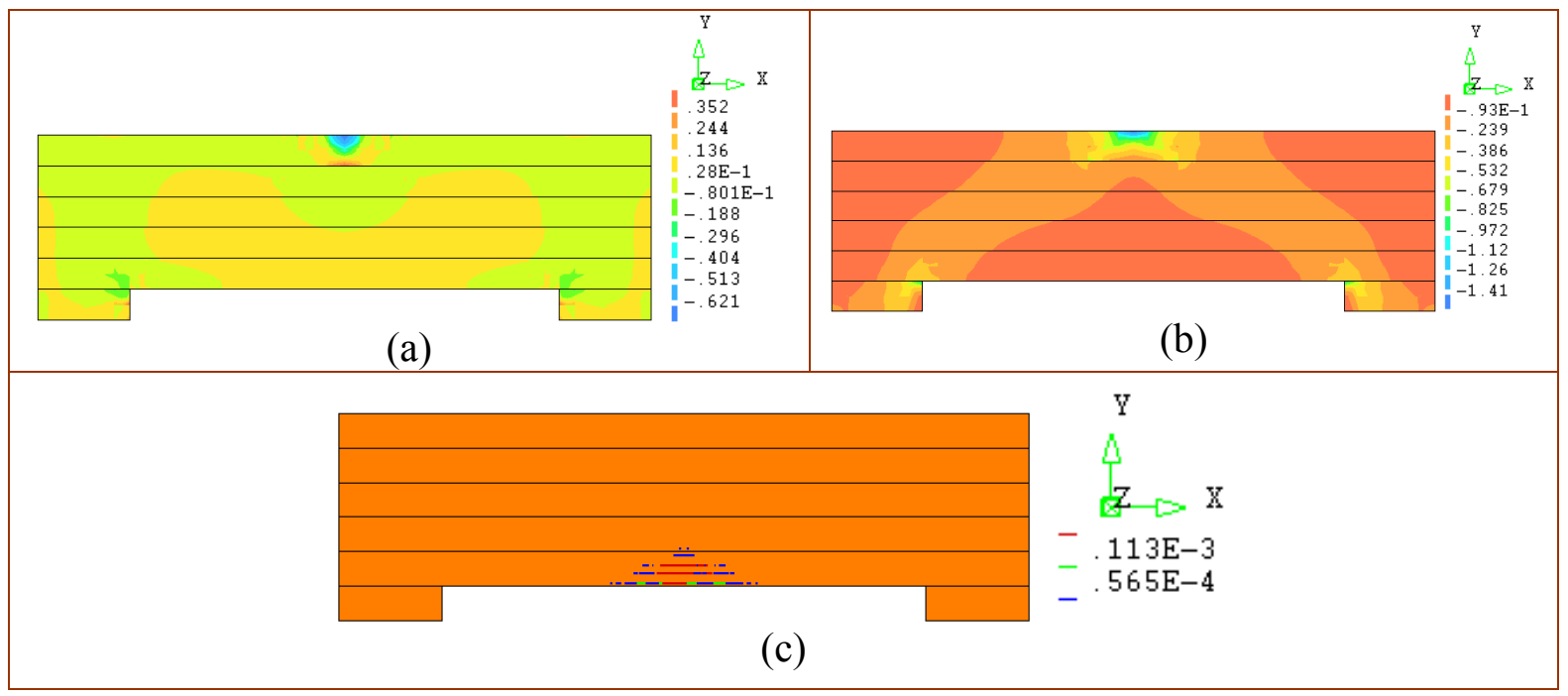

Figure 15 Numerical analysis results of Model 3 for a load of $16.5 \mathrm{kN}$ : (a) maximum principal stress, (b) minimum principal stress, (c) values of maximum principal strain in the fissures (units in $\mathrm{mm}$ and Newton). 


\section{Comparison between the results obtained from numerical simulation}

The numerical simulations of the models, with and without strengthening of the joint armor, showed similar results regarding the load level that corresponds to the occurrence of the first crack and the displacement in the center node of the three analyzed models $(0.20 \mathrm{~mm})$. The differences became significant between the models for higher levels of load.

However, the models (MOD 2 and MOD 3) showed minor differences regarding the increase of the resistance, the ductility and the tensile stress distribution in the armor at the same levels of loads.

Figure 16 shows the load versus displacement curves of the middle node for the models obtained by numerical simulation.

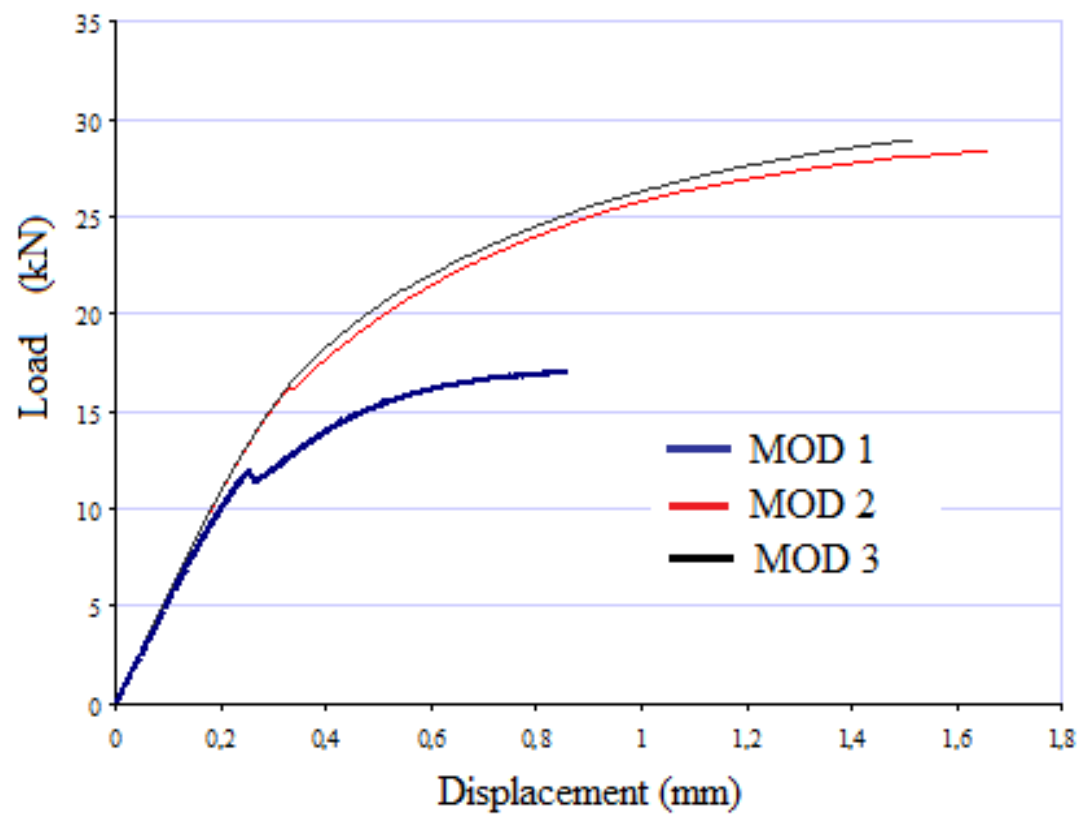

Figure 16 Curve of the central node of the models: load versus displacement.

Table 4 presents a summary of loads and deflections obtained at the first crack occurrence and at the failure of each model numerical simulated. 


\begin{tabular}{cccc}
\hline Model & $\begin{array}{c}\text { First crack } \\
\text { load } \\
(\mathrm{kN})\end{array}$ & $\begin{array}{c}\text { Deflection for } \\
\text { first crack } \\
(\mathrm{mm})\end{array}$ & $\begin{array}{c}\text { Maximum } \\
\text { deflection } \\
(\mathrm{mm})\end{array}$ \\
\hline 1 & 9,17 & 0,20 & 0,86 \\
2 & 10,6 & 0,20 & 1,65 \\
3 & 10,8 & 0,20 & 1,50 \\
\hline
\end{tabular}

Table 4 - Summary of results obtained from the numerical simulation of each model analyzed.

According to the results presented in Table 4 and Figure 16, it appears that models with armor attached to each of two horizontal rows (MOD2) showed higher ductility and a slight difference in load capacity in relation to the model with reinforcement in all horizontal joints (MOD 3).

Regarding the model without reinforcement (MOD 1), there was observed an increase in load capacity of approximately $40 \%$, whose tensile strength increased from $17.0 \mathrm{kN}(\bmod 1)$ to $28.4 \mathrm{kN}(\mathrm{MOD} 2)$.

At the occurrence of the first crack the models showed similar results regarding the load level at the same displacement of the central node $(0.20 \mathrm{~mm})$.

From figure 16 can be clearly seen significant differences of the higher loads, manly for the model without reinforcement. It can be seen that in the elastic domain that is not a significant difference between the curves, where there is not a significant phenomenon of instability yet .

The loads increased, mainly near a load level of $10 \mathrm{kN}$ (initiation of the crack in all the models), the differences become significant gradually. According to the tensions in the armor obtained from the numerical simulation, at this load level, there is a more effective participation of armor in the behavior of masonry. Thus, due to resistance mobilized by the armor after the onset of cracking, reinforced models still support significant increases in load and deformation (displacement).

It is worth note that the reduced deflection and stiffness of model 1 (MOD 1) show a brittle fracture and sharp, with no large strains are able to anticipate the collapse.

\section{Final conclusions}

According to the numerical analysis presented in this paper, it can be conclued:

- the rupture occurred due to crushing of the three models analyzed in the spread of strains of the center of the model in the direction of support; 
- that increasing the reinforcement ratio over the non-structural masonry does not lead to increased loading of the first crack. In this context, if the masonry wall is relatively rigid and mechanical strength is low, the increase in armor joint does not result in improvement in the behavior of masonry subjected to bending in its plane;

- the models with bed joint reinforcement showed an increase of the load to initiate cracking, best behavior in service, higher load capacity and greater deflection at break;

- improvements made also in relation to the ultimate limit state, which indicates that it has been winning and that bed joint reinforcement can be used in non structural masonry walls submitted to the flexion effort and structural masonry walls.

\section{References}

[1] H. Medeiros, "Excessive deformations", Magazine Téchne, Brazil, 46-51, 13 April, 2005. http://www.revistatechne.com.br/engenharia-civil/97/ artigo32870-1.asp

[2] E.D. Bastidas, L.F. Molina, L. Yamin, A. Sarria, J.P. Ortega, J.G. Tumialan, "Non-structural masonry walls strengthened with GFRP laminates". In: North American Masonry Conference p. 168-179. South Carolina, USA, 2003.

[3] E. Thomaz, P. Helene. "Quality in design and execution of masonry and structural walls in buildings". São Paulo / Brazil, EPUSP. (Technical Bulletin of the Polytechnic School of USP. Department of Civil Engineering, BT / PCC/252), 2000.

[4] P.B. Lourenço. "Concept and design for masonry wall". In: Seminar on Masonry Walls, P. B. Lourenço \& H. Sousa (Eds). p.77-110. Porto, 2002.

[5] E.A. Oliveira, "Numeric and experimental study of non structural masonry walls with bed joint reinforcement submitted to flexion in its plan". Thesis $(\mathrm{PhD})$ - School of Engineering at Federal University of Minas Gerais. Belo Horizonte / Brazil, 2009.

[6] P.B. Lourenço. "Computational strategies for masonry structures". Delft, The Netherlands, Delft University Press, 1996.

[7] DIANA-9.1. "User's Manual - Pre and Post processing". First eds. Copyright by TNO DIANA BV, 2005. 